\title{
Adding Sn on the Performance of Amorphous Brazing Fillers Applied to Brazing TA2 and Q235
}

\author{
Jie Cui' ${ }^{1}$ Qiuya Zhai ${ }^{*}$, Jinfeng Xu${ }^{1}$, Yahui Wang ${ }^{2}$, Jianlin Ye ${ }^{2}$ \\ ${ }^{1}$ Xi'an University of Technology, Xi'an, China \\ ${ }^{2}$ Xi' an Unit Container Manufacturing LTD Co., Xi'an, China \\ Email: ${ }^{*}$ qiuyazhai@xaut.edu.cn
}

Received 22 July 2014; revised 30 August 2014; accepted 18 September 2014

Copyright (C) 2014 by authors and Scientific Research Publishing Inc.

This work is licensed under the Creative Commons Attribution International License (CC BY). http://creativecommons.org/licenses/by/4.0/

(c) (i) Open Access

\begin{abstract}
Amorphous filler Ti-Zr-Cu-Ni with better performance and higher melting point than the $\alpha \rightarrow \beta$ phase transition temperature $882.5^{\circ} \mathrm{C}$ of $\mathrm{TA2}$, is appropriate for joining TC and TB titanium alloys but not for TA titanium alloys, with which the ductility of the joined base metal TA2 gets down. In this paper, $\mathrm{Sn}$ is added into $\mathrm{Ti}-\mathrm{Zr}$-Cu-Ni filler to reduce its melting temperature then to satisfy the joining temperature requirement, and the effects of the content of $S n$ on the microstructure of the alloy and brazing performance are investigated. The results show that, the Ti-Zr-Cu-Ni-Sn brazing foils still possess amorphous structure; the melting point of fillers is reducing with the increase of the Sn content; the joint gap that formed during brazing TA2 and Q235 using Ti-Zr-Cu-Ni-Sn foils is fully filled with continuous compact surface and smooth uniform fillet; the shear strength of the joint is raising with the increase of $S n$ content in brazing fillers and the strength reaches to 112 MPa when Sn content is 3\%; adding more $\mathrm{Sn}$, more brittle intermetallic compounds $\mathrm{TiFe}$ and $\mathrm{TiFe}_{2}$ are gathering to form cluster and the shear strength of the joint is reducing; the shear fracture always occurs in the center of the seam.
\end{abstract}

\section{Keywords}

Titanium TA2, Brazing, Amorphous Brazing Filler, Joint Microstructure

\section{Introduction}

Titanium alloys have high specific strength, low density, good thermostability, tenacity, thermal conductivity

*Corresponding author.

How to cite this paper: Cui, J., Zhai, Q.Y., Xu, J.F., Wang, Y.H. and Ye, J.L. (2014) Adding Sn on the Performance of Amorphous Brazing Fillers Applied to Brazing TA2 and Q235. Journal of Surface Engineered Materials and Advanced Technology, 4, 342-347. http://dx.doi.org/10.4236/isemat.2014.46038 
and high fatigue resistance but high price. Common engineering material mild steel Q235 has excellent performance but reasonable price. Therefore, the advantages of these two materials above-mentioned can be made full use of by connecting, which has high practical values and good economical benefits.

It is hard to connect titanium and mild steel for the great difference in their physical and chemical properties. There are many methods to connect titanium and titanium alloy at present, such as argon arc welding, electron beam welding, laser welding and other fusion welding; diffusion welding, friction welding, explosion welding and other solid-state joining; infrared welding, high frequency welding, vacuum brazing and other brazing [1][4]. Among them, brazing has important application in aerospace field with low welding temperature, simple equipment and process, which is applied to the connection of dissimilar metals titanium and steel and is available for the weld of precision components with complex structure and thin-wall.

There is a great variety of brazing fillers for brazing titanium and titanium alloy, such as Ag-based, Al-based, Pb-based and Ti-based brazing fillers. Among them, Ti-based brazing filler can be made into amorphous filler through rapid solidification. This kind of filler has pure uniform ingredient, low welding temperature, good wettability, brazing quality and many other outstanding merits.

In 1990, Onzawa T. et al. developed amorphous brazing filler Ti-Zr-Cu-Ni which now has become an important filler for brazing titanium and titanium alloy, and the joint can work in high temperature and highly corrosive media [5]. However, this kind of filler is mostly applied to the connection of titanium and titanium alloy, rarely to the connection of dissimilar metals titanium and steel. The melting temperatures of this kind of fillers are almost in the range of $980^{\circ} \mathrm{C}-1000^{\circ} \mathrm{C}$ much higher than the $\alpha \rightarrow \beta$ phase transition temperature of TA2. When the welding temperature is higher than $882.5^{\circ} \mathrm{C}$, titanium translates from $\alpha$ phase with close-packed hexagonal structure to $\beta$ phase with body-centered cubic structure, and then translates into acicular structure in the subsequent process of rapid solidification, which reduces the ductility of the base metal titanium near the brazing seam. Accordingly, in order to avoid the phase transformation, the melting temperature of the filler should be lowered and the brazing temperature should be controlled under the phase transformation temperature.

Adding element that reduces the brazing temperature is a good solution to this problem. Beryllium can form limit solid solution and compound with titanium and small content of it can reduce the melting temperature. Other elements such as V, Cr, Fe and Co can also have the same effect but they are not obvious [6]. Sn without poison or harm can not only reduce the melting temperature but also barely change alloy's phase composition with small content [7].

In this paper, in order to obtain an amorphous filler with excellent performance that can be applied to the brazing of TA2/Q235, amorphous filler Ti-Zr-Cu-Ni-Sn is designed; filler foils are prepared by using a single roller rapid solidification apparatus; fillers' properties are tested; the brazing of TA2/Q235 with the designed fillers is investigated; the effect of the content of Sn on microstructure and mechanical properties of the joint are analyzed.

\section{Design of Experiments}

In this experiment, element $\mathrm{Sn}$ that can lower the melting temperature is added into the master alloy $\mathrm{Ti}_{35} \mathrm{Zr}_{35} \mathrm{Cu}_{15} \mathrm{Ni}_{15}$. The compositions of six designed fillers are showed in Table 1.

Table 1. Chemical compositions of designed brazing fillers Ti-Zr-Cu-Ni-Sn.

\begin{tabular}{cccccc}
\hline \multirow{2}{*}{ Num. } & \multicolumn{5}{c}{ Elements (wt\%) } \\
\cline { 2 - 6 } & $\mathrm{Ti}$ & $\mathrm{Zr}$ & $\mathrm{Cu}$ & $\mathrm{Ni}$ & $\mathrm{Sn}$ \\
\hline 1 & 35 & 35 & 35 & 35 & 0 \\
\\
\cline { 2 - 6 } 3 & 34.65 & 34.65 & 14.85 & 14.85 & 3 \\
4 & 33.95 & 33.95 & 14.55 & 14.55 & 5 \\
5 & 33.25 & 33.25 & 14.25 & 14.25 & 7 \\
\hline
\end{tabular}


Simple metals (99.99\%) were smelted into brazing filler metal by high frequency induction heating equipment in argon atmosphere and brazing fillers were prepared by using a single roller rapid solidification apparatus [8]-[10] in this experiment. The experimental parameters can be seen in reference [9]. The brazing fillers with thickness of $40 \mu \mathrm{m}-60 \mu \mathrm{m}$ and width of $4 \mathrm{~mm}$, the biggest length just $30 \mathrm{~cm}$, and their phase structure and composition were tested by X-ray diffractometer, were studied by means of different scanning calorimeter to analyze the effect of the content of $S n$ on the melting temperature of brazing fillers.

The brazing is conducted in vacuum high frequency brazier, the brazing parameters are: vacuum degree is 0.1 $\mathrm{Pa}$; welding temperature is $800^{\circ} \mathrm{C}$; heating current is $25 \mathrm{~A}$; heating time is $15 \mathrm{~s}$; holding time is $15 \mathrm{~s}$; cooling to room temperature is in furnace. The sample made along the axis of the welded sample is etched with the solution of $3 \mathrm{ml} \mathrm{HF}+6 \mathrm{ml} \mathrm{HNO}_{3}+100 \mathrm{ml} \mathrm{H}_{2} \mathrm{O}$ [11], the effect of the content of Sn on the microstructure of the joint is analyzed by using Olympus GX-71 metallurgical microscope, the shear strength of the joints is tested by WE-100 universal testing machine and the effect of the content of Sn on the strength is analyzed.

\section{Results and Discussion}

\subsection{The Effects of Adding Sn on the Microstructure and Properties of the Brazing Fillers}

Figure 1 shows the X-ray diffraction spectrum patterns of Ti-Zr-Cu-Ni-Sn brazing fillers. In the pictures there is no peak according to crystal phase, but broad diffraction peaks belong to glassy phases only. The brazing fillers still process typical amorphous diffraction peaks when the content of Sn rises to 7\%. Besides the corresponding base peaks of the fillers with 7\% Sn, some peaks get sharp in local XRD curve of the brazing filler when the content reaches to $9 \%$. It can thus be seen that the amorphous structure of the brazing fillers cannot be changed by adding a bit Sn, but tend to be crystallized when the content increases rapidly.

Figure 2 shows the DSC curves of the three brazing filler metals. In Figure 2(a), it can be seen that the melting temperature of brazing filler $\mathrm{Ti}_{33.95} \mathrm{Zr}_{33.95} \mathrm{Cu}_{14.55} \mathrm{Ni}_{14.55} \mathrm{Sn}_{3}$ is the highest of the three, almost near the $\alpha \rightarrow \beta$ phase transition temperature $882.5^{\circ} \mathrm{C}$ of TA2.

Brazing filler $\mathrm{Ti}_{33.25} \mathrm{Zr}_{33.25} \mathrm{Cu}_{14.25} \mathrm{Ni}_{14.25} \mathrm{Sn}_{5}$ begins to melt at $843^{\circ} \mathrm{C}$ and stops melting at $862^{\circ} \mathrm{C}$ in Figure 2(b). The melting temperature interval of $843^{\circ} \mathrm{C}-862^{\circ} \mathrm{C}$, which is small, nearly meets the using demand for brazing $\alpha$-Ti and steel.

It can be seen from Figure 2(c) that brazing filler $\mathrm{Ti}_{31.85} \mathrm{Zr}_{31.85} \mathrm{Cu}_{13.65} \mathrm{Ni}_{13.65} \mathrm{Sn}_{9}$ begins to melt at $596^{\circ} \mathrm{C}$ and stops melting at $615^{\circ} \mathrm{C}$. The small melting temperature interval of $596^{\circ} \mathrm{C}-615^{\circ} \mathrm{C}$, meets the using requirement for brazing $\alpha$-Ti and steel.
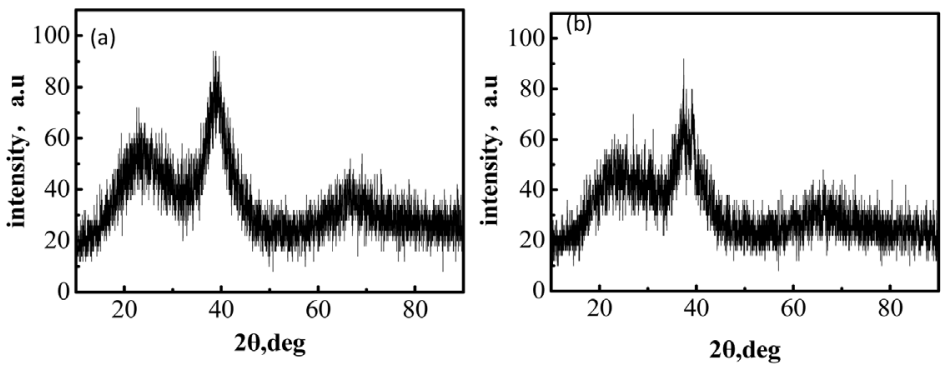

Figure 1. X-ray diffraction pattern of brazing filler metal. (a) $\mathrm{x}=7$; (b) $\mathrm{x}=9$.
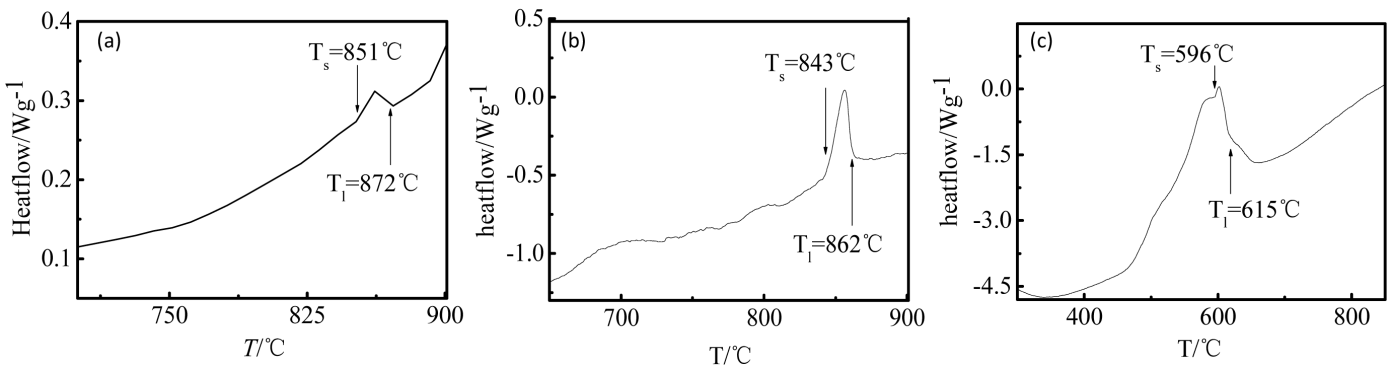

Figure 2. DSC curves of brazing ribbon of $\left(\mathrm{Ti}_{35} \mathrm{Zr}_{35} \mathrm{Cu}_{15} \mathrm{Ni}_{15}\right)_{100-\mathrm{x}} \mathrm{Sn}_{\mathrm{x}}$. (a) $\mathrm{x}=3$; (b) $\mathrm{x}=5$; (c) $\mathrm{x}=9$. 
With an increase in content of $\mathrm{Sn}$, the melting temperature is dropping. The melting point of $\mathrm{Ti}_{32.55} \mathrm{Zr}_{32.55} \mathrm{Cu}_{13.95} \mathrm{Ni}_{13.95} \mathrm{Sn}_{7}$, between the ones of $\mathrm{Ti}_{33.25} \mathrm{Zr}_{33.25} \mathrm{Cu}_{14.25} \mathrm{Ni}_{14.25} \mathrm{Sn}_{5}$ and $\mathrm{Ti}_{31.85} \mathrm{Zr}_{31.85} \mathrm{Cu}_{13.65} \mathrm{Ni}_{13.65} \mathrm{Sn}_{9}$, meets the using requirement for brazing $\alpha$-Ti and steel as well.

These brazing fillers are all viscous liquid under the welding temperature, their mobility can be measured by the viscosity of liquid metal. The bigger the viscosity is, the smaller the mobility becomes. And the viscosity is inversely proportional to the degree of superheat. Hence, with the increase of the content of Sn, the melting temperature of the alloy gets lower and the degree of superheat of the liquid metal becomes bigger, which will makes the viscosity lower, the mobility higher and then improves the spreadability of the brazing fillers under a certain welding temperature. Therefore, it can achieve the goal of reducing the melting temperature of the brazing fillers by adding $\mathrm{Sn}$ into the master alloy $\mathrm{Ti}_{35} \mathrm{Zr}_{35} \mathrm{Cu}_{15} \mathrm{Ni}_{15}$. And adding $\mathrm{Sn}$ can reduce the solidus and liquidus, shrink the melting temperature interval, improve the mobility, spreadability and welding performance of the brazing fillers [12] [13].

\subsection{The Effects of Sn Content on the Microstructure and Properties of the TA2/Q235 Joints}

The microstructure of the overlap joint TA2/ $\mathrm{Ti}_{31.85} \mathrm{Zr}_{31.85} \mathrm{Cu}_{13.65} \mathrm{Ni}_{13.65} \mathrm{Sn}_{9} / \mathrm{Q} 235$ is showed in Figure 3. Figure 3(a) shows the whole morphology of the joint. There appears to have three zones from top to bottom: base metal TA2 zone, brazing seam zone and base metal Q235 zone. The base metal TA2 near the brazing seam presents sawteeth shape for it partly converts into lath-like structure of $\beta$ phase. However, the base metal TA2 away from the brazing seam remains the original structure of $\alpha$ phase.

It can divided into three parts of the brazing seam: firstly, the wider pale zone of the seam near the side of the base metal TA2 is the transition zone of the seam and the base metal TA2, containing a lot of Ti and fewer C and Fe. Secondly, the center of the seam consists of white sheet phase and gray matrix, and the small size white phases near the center gather to form cluster; the white phases that are brittle intermetallic compounds with lager size are sparsely distributed. Comparing with that, the transition region between the seam and the base metal Q235 appears to become narrower where there is an obvious boundary.

Some points (A, B, C, D) in the seam were examined by means of SEM showed in Figure 3(b). The white sheet phases mainly consisting of more $\mathrm{Ti}, \mathrm{Fe}$ and small content of $\mathrm{Ni}, \mathrm{Cu}$ and $\mathrm{Zr}$ are $\mathrm{TiFe}$ and $\mathrm{TiFe}_{2}$. For element Fe can strongly propel $\beta$-Ti to remain at room temperature, these phases should be $\beta$-Ti solid solution including alloys. The matrix is mainly constituted by element $\mathrm{Ti}$ and lager content of $\mathrm{C}$ and $\mathrm{Fe}$ coming from the base metal Q235 which illustrates that the elements of the base metal Q235 have been well distributed into the seam.

Figure 4 shows the microstructure in the brazing seam zone of the TA2/Q235 joint with the brazing fillers including different contents of Sn. The microstructure of the TA2/Q235 joint without Sn is shown in Figure 4(a) and there appears to be some white phases distributed sparsely in the light color matrix. Figure 4(b) shows the microstructure of the TA2/Q235 joint with 5\% Sn. This seam is constituted by light and dark color matrixes and there are white phases densely distributed in the light matrix with smaller size than the white phases in Figure 4(a). The microstructure of the TA2/Q235 joint including 7\% Sn is shown in Figure 4(c). There are white phases with significant difference in size and the larger ones are sparsely distributed, the smaller ones gather to form
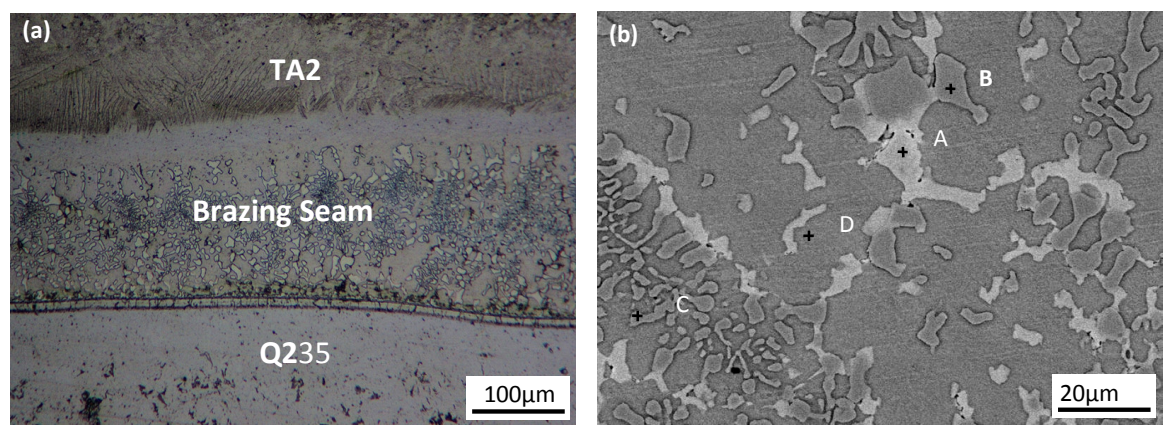

Figure 3. Microstructure of joint brazed with $\mathrm{Ti}_{31.85} \mathrm{Zr}_{31.85} \mathrm{Cu}_{13.65} \mathrm{Ni}_{13.65} \mathrm{Sn}_{9}$. (a) Microstructure of joint; (b) Microstructure of seam. 

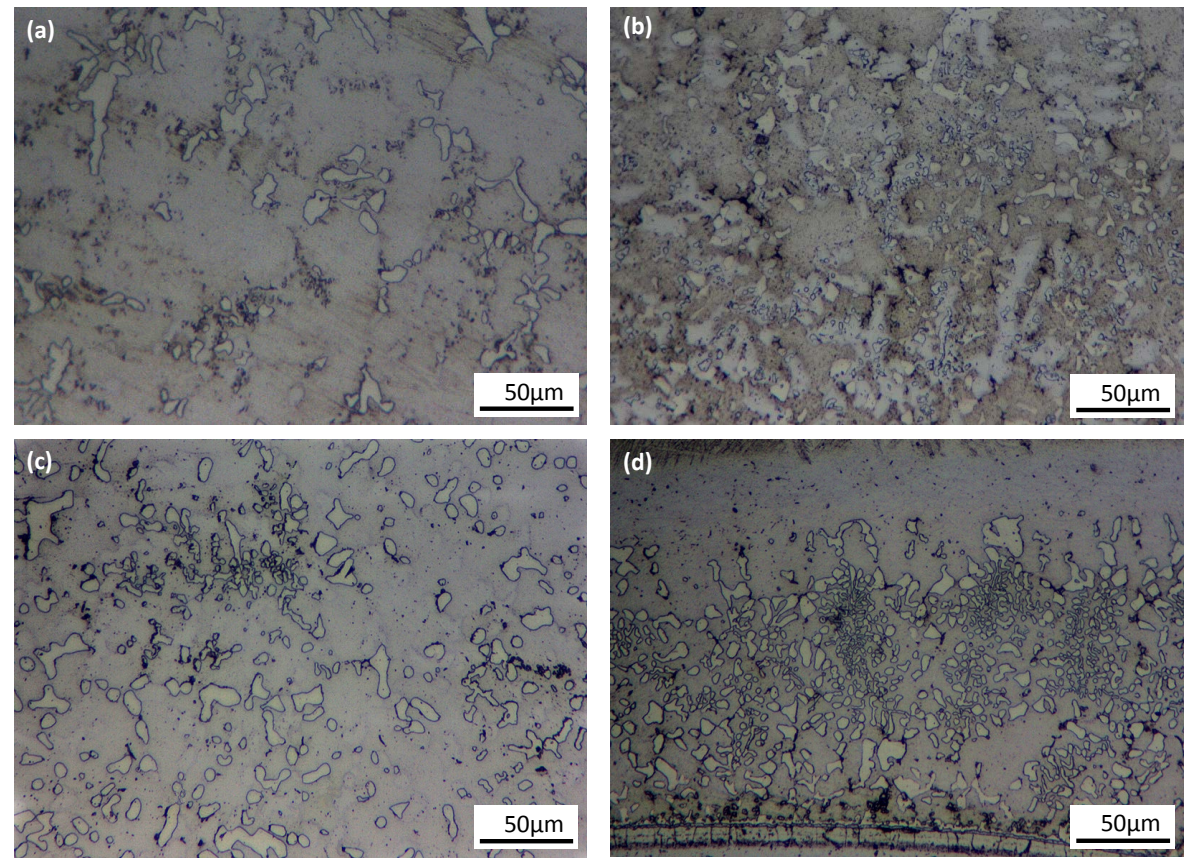

Figure 4. Microstructure of joint brazed with $\left(\mathrm{Ti}_{35} \mathrm{Zr}_{35} \mathrm{Cu}_{15} \mathrm{Ni}_{15}\right)_{100-\mathrm{x}} \mathrm{Sn}_{\mathrm{x}}$. (a) $\mathrm{x}=0$; (b) $\mathrm{x}=5$ (c) $x=7$; (d) $x=9$.

cluster. Figure 4(d) shows the microstructure of the TA2/Q235 joint with 9\% Sn. Through comparing the microstructure of the TA2/Q235 joint with the brazing fillers including different content of Sn, it can be seen that, with an increase in Sn content, the microstructures of the seams change from uniformity to layering gradually, the size of the distributed white brittle phases in the seam is being diminished, so that the more and more white phases are gathering to form cluster.

The solid solubility of $\mathrm{Fe}$ in $\alpha$-Ti is just $0.05 \%-0.1 \%$ at room temperature, not exceeding $0.5 \%$ at eutectoid temperature. Adding more $\mathrm{Sn}$ can reduces the melting temperature and the dissolution of $\mathrm{Fe}$ in $\mathrm{Ti}$ as well. When the content of $\mathrm{Fe}$ in $\beta$ - $\mathrm{Ti}$ reaches to a certain amount, during the cooling process, the oversaturation of $\mathrm{Fe}$ in $\mathrm{Ti}$ occurs. When the content of Fe exceeds its solid solubility in $\mathrm{Ti}$, the brittle intermetallic $\mathrm{TiFe}_{2}$ and $\mathrm{TiFe}$ are formed. And obviously the appearance and augment of these white brittle phases reduces the mechanical properties of the joints.

\subsection{The Effect of the Content of Sn on the Mechanical Properties of the TA2/Q235 Joints}

Figure 5 shows the shear strength curve of TA2/Q235 joints with the change of the amount of Sn. Through testing the shear strength of these TA2/Q235 joints with different contents of Sn, it is found that with an increase in the content of Sn, the shear strengths of TA2/Q235 joints firstly increase, reaching to $112 \mathrm{MPa}$, and then descend. From the appearance of the facture, it can be seen that the cracks mainly occur in the center of the seam. This is because more brittle intermetallic compounds are emerged in the center of the seam with too much more Sn than the seam without Sn, which descends the strength of the joints. And the ductility of the base metal TA2 of the joint kept by adding $S n$ to decrease the $\alpha \rightarrow \beta$ phase transition cannot compensate the harm to the property of the joints from the emerged intermetallic compounds. When the content of $\mathrm{Sn}$ is $3 \%$, the $\alpha \rightarrow \beta$ phase transition and the intermetallic compounds are both less, which enhances the strength of the joints.

\section{Conclusions}

1) In this paper, in order to reduce the melting temperature of the Ti-Zr-Cu-Ni master alloy, three brazing fillers $\left(\mathrm{Ti}_{35} \mathrm{Zr}_{35} \mathrm{Cu}_{15} \mathrm{Ni}_{15}\right)_{100-\mathrm{x}} \mathrm{Sn}_{\mathrm{x}}(\mathrm{x}=5,7,9)$ with amorphous structure are designed and prepared. With an increase in the content of $\mathrm{Sn}$, the shear strength and the melting temperature are gradually descending, satisfying the welding temperature requirement for brazing TA2/Q235. 


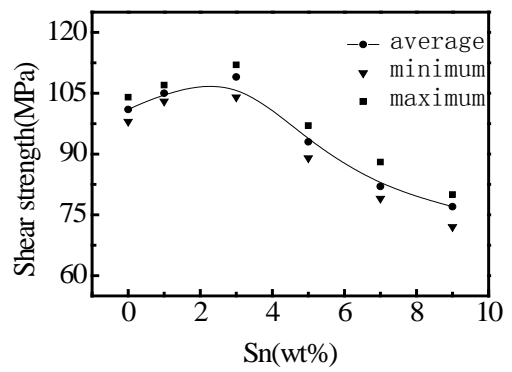

Figure 5. Influence of Sn contents on shear strength of TA2/Q235 joints.

2) The high frequency induction vacuum brazing of TA2/Q235 is conducted by using designed amorphous fillers with lower melting point, which has good performance. With an increase in the content of Sn, white brittle intermetallic compounds $\mathrm{TiFe}$ and $\mathrm{TiFe}_{2}$ with reducing size increase little by little gathering to form cluster; the shear strengths of the joints firstly increase, reaching to $112 \mathrm{MPa}$ when the Sn content is 3\%, and then descend. The cracks mainly occur in the center of the seams.

\section{Funding}

This work was supported by the scientific research project of Shaanxi province science and technology department, the service local special projects of Shaanxi province education department, the integrated innovation plan of Xi'an technology bureau and the western material innovation fund.

\section{References}

[1] Meshra, S.D. and Mohandas, T. (2010) A Comparative Evaluation of Friction and Electron Beam Welds of Near- $\alpha$ Titanium Alloy. Materials and Design, 31, 2245-2252. http://dx.doi.org/10.1016/j.matdes.2009.10.012

[2] Liu, J., Watanabe, I. and Yoshida, K. (2002) Joint Strength of Laser-Welded Titanium. Dental Materials, 18, $143-148$. http://dx.doi.org/10.1016/S0109-5641(01)00033-1

[3] Chang, C.T., Du, Y.C. and Shiue, R.K. (2006) Infrared Brazing of High-Strength Titanium Alloys by Ti-15Cu-15Ni and Ti-15Cu-25Ni Filler Foils. Materials Science and Engineering, 420, 155-164. http://dx.doi.org/10.1016/j.msea.2006.01.046

[4] Elrefaey, A. and Tillmann, W. (2007) Interface Characteristics and Mechanical Properties of the Vacuum-Brazed Joint of Titanium-Steel Having a Silver-Based Brazing Alloy. Metallurgical and Materials Transactions, 38, 2956-2961. http://dx.doi.org/10.1007/s11661-007-9357-5

[5] Shapiro, A.E. and Flom, Y.A. (2012) Brazing of Titanium at Temperature below $800^{\circ} \mathrm{C}$ : Review and Prospective Applications. Welding Journal, 50, 1-22.

[6] Chang, C.T., Shiue, R.K. and Chang, C.S. (2005) Microstructural Evolution of Infrared Brazed Ti-15-3 Alloy Using Ti-15Cu-15Ni and Ti-15Cu-25Ni Fillers. Scripta Materialia, 54, 853-858. http://dx.doi.org/10.1016/j.scriptamat.2005.11.013

[7] Qi, Y., Zhang, Y.H. and Quan, B.Y. (2003) Development and Application of Braze Welding and Ti-Based Braze Material. Metallic Functional Materials, 10, 31-37.

[8] Huang, Y.J., et al. (2008) Formation, Thermal Stability and Mechanical Properties of $\mathrm{Ti}_{42.5} \mathrm{Zr}_{7.5} \mathrm{Cu}_{40} \mathrm{Ni}_{5} \mathrm{Sn}_{5} \mathrm{Bulk}_{\mathrm{Me}} \mathrm{Me}$ tallic Glass. Science in China Series G: Physics, Mechanics Astronomy, 51, 372-378. http://dx.doi.org/10.1007/s11433-008-0049-y

[9] Xu, J.F. and Wei, B.B. (2004) Liquid Phase Flow and Microstructure Formation during Rapid Solidification. Acta Physica Sinica, 53, 160-166.

[10] Threadgill, P.L. and Dance, B.C.I. (1971) Joint of Intermetallic Alloys Further Studies. Welding Journal, 50, 379.

[11] Onzawa, T., Suzumura, A. and Ko, M. (2012) Structure and Mechanical Properties of CP Ti and Ti-6Al-4V Alloy Joints Brazed with Ti-Based Amorphous Filler Metals. Japan Welding Society, 5, 205-211.

[12] Botstein, O. and Rabinkin, A. (1994) Brazing of Titanium-Based Alloys with Amorphous Ti-25Zr-50Cu Filler Metal. Materials Science and Engineering A, 188, 305-315. http://dx.doi.org/10.1016/0921-5093(94)90386-7

[13] Howden, D.G. and Monroe, R.W. (1972) Suitable Alloys for Brazing Titanium Heat Exchangers. Welding Journal, 51, 31-36. 
Scientific Research Publishing (SCIRP) is one of the largest Open Access journal publishers. It is currently publishing more than 200 open access, online, peer-reviewed journals covering a wide range of academic disciplines. SCIRP serves the worldwide academic communities and contributes to the progress and application of science with its publication.

Other selected journals from SCIRP are listed as below. Submit your manuscript to us via either submit@scirp.org or Online Submission Portal.
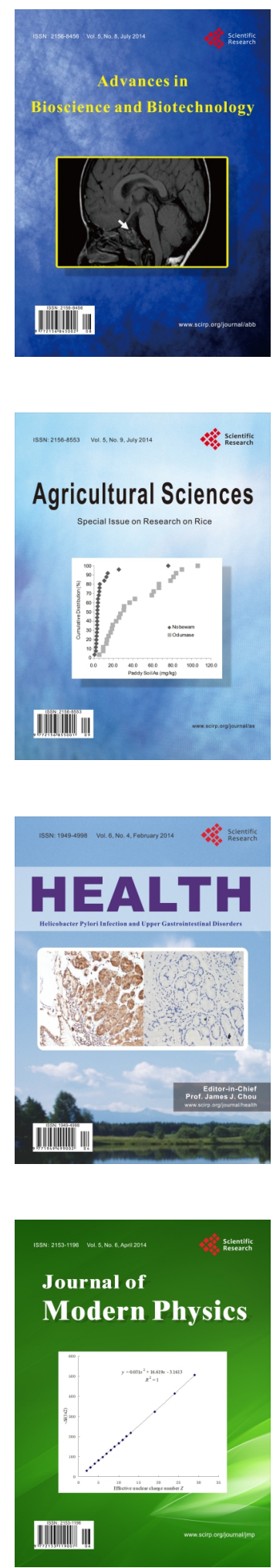
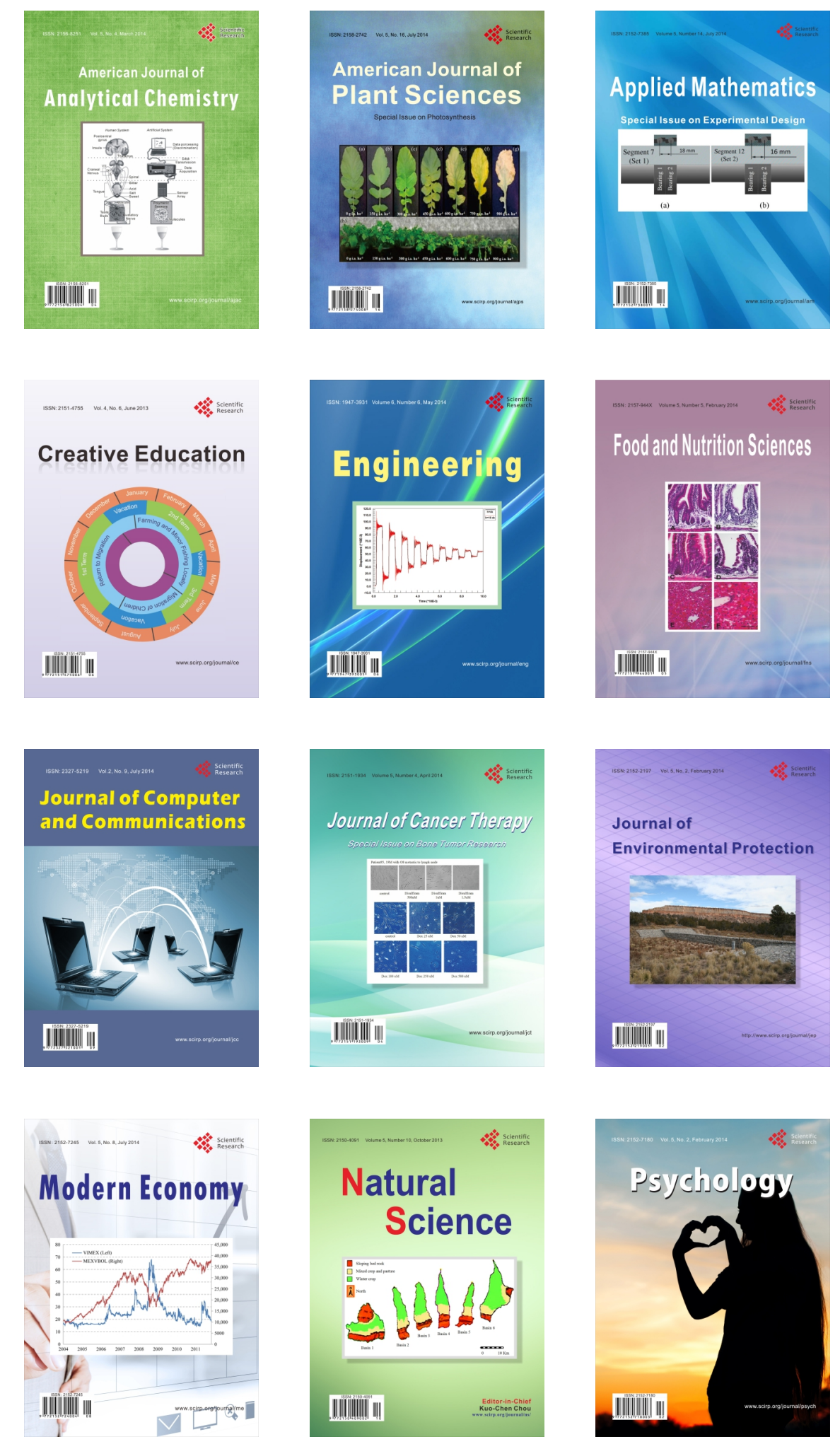